Prevention of diabetic nephropathy with enalapril in normotensive diabetics with microalbuminuria. B.117 1988;297:1092-5.

42 Viberti GC, Pickup JC, Jarett RJ, Keen H. Effects of control of blood glucose on urinary excretion of albumin and heta ${ }_{2}$-microglobulin in insulin dependent diabetes. N Engl F Med 1979;300:638-41.

43 Cohen D, Dodds R, Viberti GC. Effect of protein restriction in insulin dependent diabetics at risk of nephropathy. B.MF 1987;294:795-8.

44 Mathiesen ER, Hommel E, Olsen UB, Parving $\mathrm{H}-\mathrm{H}$. Elevated urinary prostaglandins and the effect of indomethacin on kidney function in incipient diabetic nephropathy. Diabetic Med 1988:5:145-9.

45 Anderson S, Rennke HG, Garcia DL., Brenner B. Short and long term effects of antihypertensive therapy in the diabetic rat. Kidney Int 1989:36:526-36.

Fogo A, Yohida Y, (Glick AD, Homma T, Ichikawa J. Serial micropuncture analysis of glomerular function in two rat models of glomerular sclerosis. 7 Clin Invest 1988:82:322-30.

47 Cooper ME, Allen TJ, Macmillan PA, Clarke BE, Jerums G, Doyle AE.
Enalapril retards glomerular basement thickening and albuminuria in the diabetic rat. Diabetologia 1989;32:326-8.

48 Morelli E, Loon N, Meyer T, Peters W, Meyers BD. Effects of convertingenzyme inhibition in diabetic glomerulopathy. Diabetes 1990;39:76-82.

49 Mauer SM, Steffes MW, Ellis EN, Sutherland DER, Brown DM, Goetz FC. Structural-functional relationships in diabetic nephropathy. $\mathcal{F}$ Clin Invesi 1984;74:1143-55.

50 Østerby R, Parving H-H, Nyberg G, Hommel E, Jørgensen HE, Løkkegård $\mathrm{H}$, et al. A strong correlation between glomerular filtration rate and filtration surface in diabetic nephropathy. Diabetologia 1988;31:265-70.

51 Chavers BM, Bilous RW, Ellis EN, Steffes MW, Mauer SM. Glomerular lesions and urinary albumin excretion in type 1 diabetes without overt proteinuria. N Engl f Med 1989;320:966-70.

(Accepted 10 Mav 199I)
Department of Diagnostic Radiology, Turku University Hospital, SF20520 Turku, Finland Timo Kallio, MD, junior hospital medical officer

BMf 1991;303:87-9

\title{
Assessment of blood echogenicity as an alternative measure to erythrocyte sedimentation rate
}

\author{
Timo Kallio
}

\begin{abstract}
Objective-To determine the relation between erythrocyte sedimentation rate and blood echogenicity and whether measurement of erythrocyte sedimentation rate could be replaced by measurement of blood echogenicity in monitoring acute phase reactions.

Design-Simultaneous measurement of echogenicity of flowing blood and erythrocyte sedimentation rate in blood samples and comparison of results.
\end{abstract}

Setting - A radiological department in a university hospital.

Subjects -83 patients with a suspected venous thrombosis and $\mathbf{3 6}$ healthy volunteers.

Main outcome measures-Correlations between the erythrocyte sedimentation rate, packed cell volume, and echogenicity of flowing blood.

Results-Blood echogenicity correlated poorly with the packed cell volume, but strongly correlated with the erythrocyte sedimentation rate (when the packed cell volume was within reference limits) (correlation coefficient $=0 \cdot 73$ ). Blood samples with a greatly raised erythrocyte sedimentation rate were highly echogenic. Only one of the $\mathbf{3 0}$ samples with an erythrocyte sedimentation rate below $10 \mathrm{~mm}$ in first hour had a higher echogenicity than the least echogenic sample of the 19 with a sedimentation rate above $30 \mathrm{~mm}$ in first hour.

Conclusions-Echogenicity of flowing blood correlates with the erythrocyte sedimentation rate and its measurement may compete with conventional methods for evaluating the long term changes in acute phase reactions. Also, it has the added advantage that non-invasive in vivo measurements of blood echogenicity may become possible.

\section{Introduction}

The plasma concentration of macromolecules increases during the acute phase response to infection. This enhances the aggregation of red blood cells, raising the amount of sedimentation. ${ }^{1}$ The rate of erythrocyte sedimentation is used as a universal routine screening test and a measure of the progress of some inflammatory diseases. The reliability of the test is hampered by its dependence on packed cell volume and lack of specificity; several methods have been developed to overcome these disadvantages, but none has gained wide use. ${ }^{23}$

Erythrocyte aggregation causes appreciable variability in ultrasonic scattering by blood. ${ }^{+-6}$ The echogenicity of erythrocytes is related to the size of the aggregates. Alanen and I have developed a method for measuring the echogenicity of flowing blood in vitro. ${ }^{8}$ In the present study I examined the relation between the erythrocyte sedimentation rate and blood echogenicity.

\section{Materials and methods}

By a standard method (with a Vacutainer, Becton Dickinson, France) $15 \mathrm{ml}$ of venous blood was drawn from each of 139 subjects into heparinised evacuated containers. Subjects comprised 101 patients with a presumptive diagnosis of venous thrombosis in the leg and 38 healthy volunteers. The blood was stored at room temperature. All of the tests were completed within two hours.

The erythrocyte sedimentation rate of the samples was measured by the Guest method (with a Dispette, Guest Medical and Dental Products, Switzerland), which correlates well $(r>0.9)$ with the Westergren method. ${ }^{9}$ The packed cell volume of each sample was also determined.

The echogenicity of the undiluted samples was measured by a computerised method ${ }^{8}$ : a calibrated peristaltic pump established a flow of $3.8 \mathrm{~mm} / \mathrm{s}$ in a measuring chamber with a diameter of $5 \mathrm{~mm}$, corresponding to a shear rate of $4 / \mathrm{s}$. Ultrasonic echoes were registered with a single crystal unfocused $6 \mathrm{MHz}$ transducer. Each recording lasted for four seconds and produced $20 \mathrm{~A}$-mode curves, which were digitised at $20 \mathrm{MHz}$ and transferred to the computer memory and stored on floppy discs for further analysis by integration

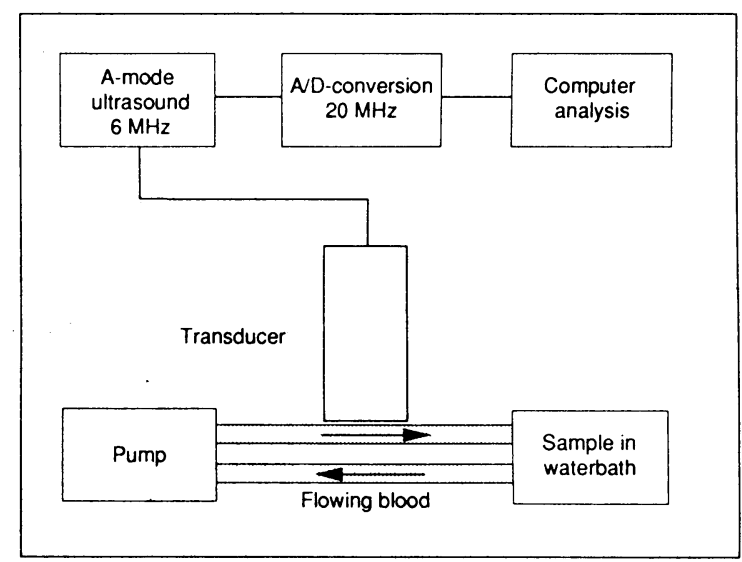

FIG 1-Ultrasonic method for measuring blood echogenicity 
of the curves after digital subtraction of chamber echoes (fig 1). Measurements were made at $37^{\circ} \mathrm{C}$.

A multiple linear regression analysis was performed to study the relations between echogenicity, sedimentation rate, and packed cell volume. An intraclass correlation coefficient was used to describe the within subject component of variance of four different blood samples from the same subject in a series of four subjects.

Four different blood samples from the same subject in a series of four subjects (all healthy volunteers) were examined at intervals of 30 minutes to study the reproducibility of the method.

\section{Results}

Twenty subjects were excluded because of failure to measure the packed cell volume $(n=5)$, the sample volume was too small $(n=8)$, contamination of the sample $(n=2)$, leakage of the tubing $(n=2)$, and other recording errors $(n=3)$. The mean (standard deviation, range) age of the 119 remaining subjects ( $47 \mathrm{men}, 72$ women) was $52(15 \cdot 2,22-85)$ years. Mean (SD, range) measurements for erythrocyte sedimentation rate were $25 \cdot 5(25 \cdot 1,1-137) \mathrm{mm}$ in first hour and for packed cell volume $0.42(0.07,0 \cdot 23-0.61)$. Thirty samples had an erythrocyte sedimentation rate below $10 \mathrm{~mm}$ in first hour and 19 a rate above $30 \mathrm{~mm}$ in first hour.

Blood echogenicity varied considerably. The mean (SD) echogenicity on the relative scale used was 5390 (2433). The ratio of highest to lowest echogenicity was $11 \cdot 6$.

I performed a multiple linear regression analysis to determine the dependency of blood echogenicity on erythrocyte sedimentation rate and packed cell volume. Having allowed for logarithm of sedimentation rate, blood echogenicity no longer depended on packed cell volume. Because the erythrocyte sedimentation rate is affected by an abnormal packed cell volume only samples with a normal packed cell volume $(0 \cdot 36-0 \cdot 55)$ were included in final analysis $(n=98)$.

There was an almost linear correlation between blood echogenicity and the logarithm of erythrocyte sedimentation rate (Pearson linear correlation coefficient 0.73 ). The linear regression line is defined by the equation $\mathrm{E}=4477 \times \log (\mathrm{ESR})-30$, where $\mathrm{E}$ is blood echogenicity and ESR is erythrocyte sedimentation rate (fig 2). The standard error of the coefficient is 425 and the residual standard deviation 1654 .

The within subject component of variance was $12.5 \%$ of the total variance. The intraclass correlation coefficient was $89 \%$ (one sided $95 \%$ confidence interval $>74 \%$ ) (table).

Only one of the 30 samples with an erythrocyte sedimentation rate below $10 \mathrm{~mm}$ in first hour had a

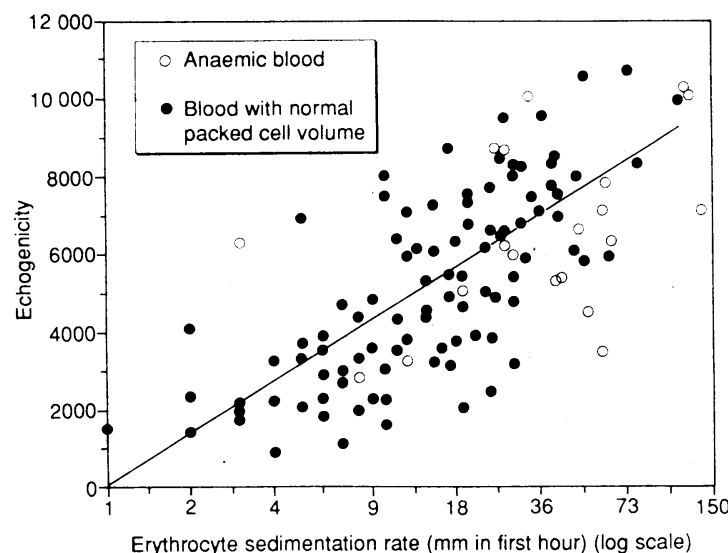

FIG 2-Variation between blood echogenicity and erythrocyte sedimentation rate (logarithmic scale) for anaemic blood samples and samples with normal packed cell volume. (Linear correlation coefficient $=$ $0 \cdot 73$ ) l'ariation in relative blood echogenicity between four samples from same volunteer subjects $(A-D) \star$

\begin{tabular}{|c|c|c|c|c|}
\hline & Subject A & Subject B & Subject C & Subject I) \\
\hline Sample 1 & 3629 & 4076 & 5996 & 8203 \\
\hline Sample 2 & 2332 & 3869 & 7059 & 9862 \\
\hline Sample 3 & 2876 & 5760 & 5579 & 8467 \\
\hline Sample 4 & 2276 & 3037 & 4771 & 8410 \\
\hline Mean value & 2778 & 4186 & 5851 & 8736 \\
\hline $\begin{array}{l}\text { Erythrocyte sedimentation } \\
\text { rate }(\mathrm{mm} \text { in first hour) }\end{array}$ & 7 & 13 & 16 & 41 \\
\hline
\end{tabular}

$\star W$ ithin subjects component of variance $=12 \cdot 5 \%$ of the total variance

higher echogenicity than the least echogenic sample of the 19 with a sedimentation rate above $30 \mathrm{~mm}$ in first hour.

\section{Discussion}

The measurement of erythrocyte sedimentation rate has been used to detect immunological, infective, ischaemic, malignant, and traumatic processes. As a screening test for acute phase response it has often been criticised, but is difficult to dislodge. ${ }^{10}$ Its most important disadvantages are its dependence on packed cell volume, difficulties with quality control, and the long duration of the test. ${ }^{3}$ However, the International Committee for Standardisation in Haematology recommends the measurement of erythrocyte sedimentation rate together with plasma viscosity as the best method for monitoring long term changes in concentrations of proteins in the acute phase. ${ }^{11}$

Erythrocyte aggregation is the basis for blood echogenicity. An index of red blood cell aggregation can be measured by determining whole blood echogenicity. The method detects very small changes in the concentration of macromolecules in the plasma. ${ }^{8}$ Blood echogenicity is fairly independent of packed cell volume over a range from $0 \cdot 10$ to $0 \cdot 80 . .^{1213}$ In a study on porcine blood there was no correlation between ultrasonic backscatter and packed cell volume at low shear rates. ${ }^{14}$ In the present study there was no correlation between packed cell volume and blood echogenicity. At raised sedimentation rates anaemic blood seemed to be less echogenic than normal blood of similar sedimentation rate (fig 2): the mean echogenicity of anaemic samples was $82 \%$ of that of normal blood when compared in samples with a high sedimentation rate ( $>50 \mathrm{~mm}$ in first hour).

Blood echogenicity is affected by several other factors in addition to plasma concentration of macromolecules. The most important of these are blood flow conditions, ${ }^{4 \times}$ ultrasonic variables, ${ }^{5}$ and blood temperature. ${ }^{15}$ These should be standardised for echogenicity measurements.

The question of quality control of the ultrasonic method for determining erythrocyte sedimentation rate has not yet been solved. Standardised suspensions of microparticles in precise concentrations or erythrocyte suspensions with known and constant fibrinogen concentration may be used for this purpose.

The order of the four measurements in the same subject had no effect on the results (see table). Although repeated measurements of echogenicity gave similar values, the reproducibility of the system needs to be improved. This problem is intraindividual variation, which could be partly solved by prolonging the sampling time to several times longer than one revolution of the roller pump.

Measurement of blood echogenicity can detect samples with considerably raised erythrocyte sedimentation rate $(>30 \mathrm{~mm}$ in first hour). The 19 of such samples in this study were always very echogenic (relative echogenicity $>5500$ ), while samples with a low sedimentation rate ( $<10 \mathrm{~mm}$ in first hour) had a low echogenicity. In fact, in all of the samples with a low sedimentation rate the echogenicity was less than 
$5000(n=30)$ except in one sample. Thus there was practically no overlapping between these groups. In the intermediate range there was more variation.

Measurement of blood echogenicity could be developed into a fast method for monitoring certain inflammatory diseases and is fairly independent of packed cell volume; the information obtained is similar to that given by the erythrocyte sedimentation rate. Measuring blood echogenicity also allows study of the tendency for erythrocyte aggregation in relation to shear rate, which may be a potentially important variable of blood rheology. A further advantage is that, in theory, blood echogenicity can be measured noninvasively in vivo.

I thank Juhani Tuominen for statistical advice. This study was supported by the Technology Development Center Helsinki, Finland.

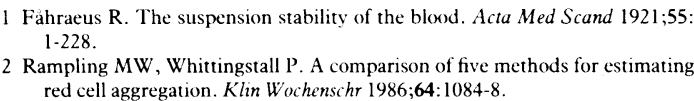

3 Stuart J, Lewis SM. Monitoring the acute phase response. BMF 1988;297: $1143-4$

Sigel B, Machi J, Beitler JC, Justin JR. Red cell aggregation as a cause of bloodflow echogenicity. Radiology 1983;148:799-802.

5 Shung KK. Physics of blood echogenicity. Fournal of Cardiovascular Ultrasonography 1983;2:401-6.

6 Shung KK. Ultrasonic characterization of biological tissues. $f$ Biomech Eng 1985; 107:309-14.

7 Alanen A, Kormano M. Ultrasonic echoes registered from erythrocytes. Invest Radiol 1985;20:521-4.

8 Kallio $T$, Alanen A. A new ultrasonic technique for quantifying blood echogenicity. Invest Radiol 1988;23:832-5.

9 Neijadlik DC, Engelhardt C. An evaluation of the Guest method for determining erythrocyte sedimentation rate. Am $\mathcal{F}$ Clin Pathol 1977;68: 766-8.

10 The ESR - an outdated test? [editorial]. Lancet 1982;i:377.

11 International Committee for standardization in haematology (expert panel on blood rheology). Guidelines on selection of laboratory tests for monitoring the acute phase response. $\mathcal{F}$ Clin Pathol 1988;41:1203-12.

12 Borders SE, Fronek A, Kemper WS, Franklin D. Ultrasonic energy backscattered from blood. An experimental determination of the variation of sound energy with hematocrit. Ann Biomed Eng 1978;6:83-92.

13 Wolverson MK, Nouri S, Joist JH, Sundaram M, Heiberg E. The direct visualization of blood flow by real-time ultrasound: clinical observations and underlying mechanisms. Radiology 1981;140:443-8.

14 Yuan YW, Shung KK. Ultrasonic backscatter from flowing whole blood. I: Dependence on shear rate and hematocrit. F Acoust Soc Am 1988:84:52-8.

15 Sigel B, Coelho JCU, Schade SG, Justin J, Spigos DG. Effect of plasm proteins and temperature on echogenicity of blood. Invest Radiol 1982;17: 29-33.

Accepted 10 May 1991)

\section{Department of Epidemiology and Population Sciences, London School of Hygiene and Tropical Medicine, London) \\ M J Shipley, MSC, lecturer in medical statistics \\ S J Pocock, PHD, professor of medical statistics \\ Department of Community Medicine, University College London, London WC1E 6EA \\ M G Marmot, FFPHM, head of department}

\section{Correspondence to:}

Professor Marmot.

BMF 1991:303:89-92

\section{Does plasma cholesterol con
coronary heart disease in eld
Whitehall study)/}

\section{Abstract}

Objective-To explore the extent to which the relation between plasma cholesterol concentration and risk of death from coronary heart disease in men persists into old age.

Design-18 year follow up of male Whitehall civil servants. Plasma cholesterol concentrations and other risk factors were determined at first examination in 1967-9 when they were aged 40-69. Death of men up to 31 January 1987 was recorded.

Subjects-18296 male civil servants, 4155 of whom died during follow up.

Main outcome measures-Cause and age of death. Cholesterol concentration in 1967-9 and number of years elapsed between testing and death.

Results -1676 men died of coronary heart disease. The mean cholesterol concentration in these men was $0.32 \mathrm{mmol} / \mathrm{l}$ higher than that in all other men ( $95 \%$ confidence interval 0.26 to $0.37 \mathrm{mmol} / \mathrm{l}$ ) This difference in cholesterol concentrations fell $0.15 \mathrm{mmol} / \mathrm{l}$ with every 10 years' increase in age at screening. The risk of raised cholesterol concentration fell with age at death. Compared with other men cholesterol concentration in those who died of coronary heart disease was $0.44 \mathrm{mmol} / 1$ higher in those who died aged $<60$ and $0.26 \mathrm{mmol} / \mathrm{l}$ higher in those aged 60-79 $(p=0.03)$. For a given age at death the longer the gap between cholesterol measurement and death the more predictive the cholesterol concentration, both for coronary heart disease and all cause mortality (trend test $p=0.06$ and 0.03 respectively).

Conclusion-Reducing plasma cholesterol concentrations in middle age may influence the risk of death from coronary heart disease in old age.

\section{Introduction}

Much international effort is being put into changing plasma cholesterol concentrations of whole popula- tions to prevent coronary heart disease. ${ }^{1}$ There is therefore much interest in whether total cholesterol concentration in plasma predicts coronary heart disease in elderly people. In the Framingham study serum cholesterol concentration became less important as a risk factor as the population aged, ${ }^{1}$ although other studies do not agree with this finding. ${ }^{2}$ If risk factors do not predict disease in elderly people there is little justification for attempting to reduce these risk factors in elderly people.

Most studies examining the predictive value of cholesterol concentration in older people had short follow up so that the age at which cholesterol concentration was measured and the age at death were close. The 18 year follow up of civil servants in the Whitehall study $^{3}$ enables us to examine how cholesterol concentrations at younger age predict death from coronary disease occurring considerably later.

\section{Subjects and methods}

In the Whitehall study 19018 male civil servants aged 40 to 69 were examined during 1967-9. ${ }^{3}$ The plasma cholesterol concentrations of 18309 men were measured at entry to the study in a capillary blood sample by using the then standard Technicon method $\mathrm{N} \mathrm{24a}{ }^{+}$These cholesterol measurements may have been too low for technical reasons, and the overall mean of $5.10 \mathrm{mmol} / 1$ in these men is probably an underestimate by $10-15 \%$. The records of the men held at the NHS Central Register were flagged and we were notified of deaths of these men up to 31 January 1987. During this period 13 men died of unknown causes, and we therefore excluded them from all cause-specific analyses. The remaining $18296 \mathrm{men}$, who have been followed for a minimum of 18 years since the initial screening, formed the basis for our analysis.

To distinguish between age at screening and age at risk (age at death) during the subsequent follow up, each subject's total follow up period was partitioned 